\title{
man \\ 25 ANYS DE L'ASSOCIACIÓ DE MESTRES: EL MOVIMENT DE RENOVACIÓ PEDAGÒGICA
}

\author{
Moviment de Renovació Pedagògica del Camp de Tarragona
}

Una associació sorgeix a partir de l'agrupació voluntària d'un conjunt de persones que s'uneixen lliurement per aconseguir unes fites que transcendeixen les seves possibilitats individuals. Per arribar a aconseguir aquestes fites s'utilitzen diferents mitjans, que es modifiquen en cada època històrica. Sense cap mena de dubte, a Catalunya l'associacionisme ha estat força determinat per les condicions històriques i per les característiques peculiars de les nostres institucions.

Des dels Ateneus de mitjans del segle XIX, nascuts al caliu de la Renaixença literària amb l'objectiu de millorar el nivell cultural dels seus associats mitjançant l'organització de conferències, cursos, seminaris, etc. dels quals en tenim una bona mostra a Reus amb el Centre de Lectura, del 1859 fins a les cooperatives, orfeons, i tot tipus d'associacions que creixeran durant la Segona República, Catalunya serà una nació amb un ric teixit associatiu i una intensa intervenció ciutadana.

\section{La primera Escola de Mestres}

L'impuls de la renovació pedagògica és potser una de les conseqüències en un darrer estadi d'aquest fenomen que s'estenia per tots els àmbits de la cultura i de la societat, i que a l'escola es multiplicava amb una voluntat de progrés social. És important recordar l'interès dels nostres mestres pels avenços que es donaven arreu d'Europa i Amèrica i l'interès de les institucions públiques -la Diputació, la Mancomunitat, l'Ajuntament de BarceIona i més tard la Generalitat-, per donar suport als esmentats avenços. En la memòria de tothom hi ha persones com Julià López, Ventura Gassol, Àngels Garriga, Dolors Canals, i més propers, Alexandre Galí, Rosa Sensat, Anna Rubiès.

La repressió ocasionada per la dictadura franquista va anul-lar aquest dinamisme associatiu i va interrompre aquest procés de renovació pedagògica, que no tornarà a sorgir fins l'any $1965 \mathrm{amb}$ el naixement i desenvolupament del primer Moviment de Renovació Pedagògica, l'Escola de Mestres Rosa Sensat.

Com diu Marta Mata: "La llavor que ja havia fructificat va seguir fent-ho. Arreu de Catalunya van néixer Escoles d'Estiu organitzades i, no cal dir-ho, mantingudes pels mateixos mestres, entestats en el treball de fer, a contracorrent de la reacció imperant, una bona escola al servei de la recuperació del temps perdut i de l'assoliment d'un futur digne per a l'escola i el país" (1990).

És en aquest context que l'any 1972 neix L'Associació de Mestres del Camp de Tarragona per a la Renovació Pedagògica, el MRP.

Creiem que és important recordar d'on venim -"Qui perd els orígens perd la seva identitat"-, per saber qui som i què volem.

\section{Qui som}

Som un moviment sòcioeducatiu que pretén potenciar la millora i la qualitat de l'educació en tots els nivells educatius i impulsar l'elaboració de propostes de reflexió i acció. Ho fem establint àmbits de cooperació i d'intercanvi entre totes les entitats i institucions que promouen aquesta millora i creant un estat d'opinió i uns referents col-lectius que identifiquin el conjunt d'iniciatives que es donen en els diversos àmbits i nivells del Sistema Educatiu (Primer Congrés de Renovació Pedagògica 1996).

No podem oblidar un dels nostres trets d'identitat, la formació permanent del professorat, perquè aquest és un dels aspectes inherents a la professió docent i ha estat una de les nostres tasques més importants. El nostre model de formació permanent potencia les activitats organitzades de forma autònoma pel professorat a partir de les necessitats que genera la seva pràctica docent, s'emmarca dins del paradigma de la investigació-acció, i vol potenciar una cultura de la formació lligada a la renovació pedagògica, al projecte de centre, al treball en equip i a la millora i transformació de les pràctiques quotidianes. És per això que, malgrat la gran quantitat d'oferta formativa que ens ofereixen als mestres, des de diferents institucions, la nostra oferta és vàlida i necessària.

Una part molt important d'aquesta constitució d'uns referents col-lectius s'ha de realitzar a partir dels intercanvis d'experiències entre els centres educatius, $\mathrm{i}$ així contribuir a la creació i difusió de la Xarxa de la Renovació Pedagogica de Catalunya. Aquesta xarxa ha de ser el marc referencial per estructurar un corrent a 


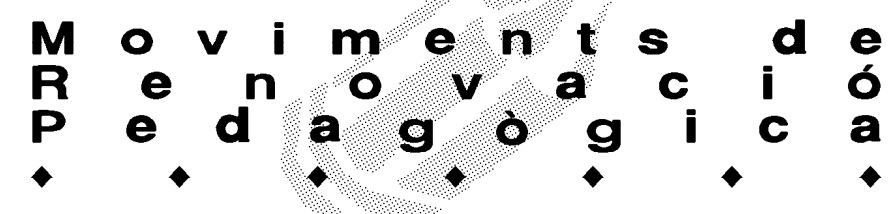

favor de la qualitat.

La coordinació de centres educatius que comparteixen aquests objectius i l'establiment d'espais de col-laboració entre la universitat $i$ els centres educatius contribuirà a superar l'aïllament de les actuacions i facilitarà l'intercanvi entre els centres educatius, entre l'educació formal i no formal, i entre tots els nivells i etapes (Primer Congrés de Renovació Pedagògica).

Per tot aquest passat viscut, amb totes aquestes idees $\mathrm{i}$ projectes per al futuri amb la ferma creença que els Moviments de Renovació Pedagògica han de ser considerats com a patrimoni comú del conjunt de la comunitat educativa, fem l'equipatge necessari per viatjar amb vosaltres durant tot l'any, tot recordant les paraules del poeta:

¡Oh la continuidad de la esperanza!

En donde algunos faltan, ya hay otros trabajando,

$y$ es rítmico el latido, y es continuo el empuje.

Las resistencias tensan

el sistema secreto de la luz temblorosa

y un diamante escondido reluce en las tinieblas

de la oceánica joya.

Un orden clandestino se estatuye.

...late la relación de mil esfuerzos,

la gloria colectiva, la operante esperanza,

la vida a cada instante perdida i recobrada.

(Gabriel Celaya).

No seria un projecte com cal si no ens haguéssim plantejat uns objectius generals i amb la il-lusió d'aconseguir-los al llarg del curs.

El projecte s'articula al voltant de tres eixos o àmbits d'actuació, que són: l'eix lúdic, l'eix pedagògic i un àmbit de tipus més general. És per això que els objectius aniran enfocats a aquest tres àmbits.

\section{Objectius a assolir}

1. Organitzar activitats adreçades als diferents membres de la comunitat educativa, especialment als $\mathrm{i}$ les alumnes i professorat, demanant la participació $i$ col-laboració de les escoles i centres d'Ensenyament Secundari, per tal que posin el seu granet de sorra a la celebració d'aquests 25 anys.

2. Motivar els centres educatius del Camp de Tarragona, amb el suport dels Serveis Educatius -Camps d'Aprenentatge i Centres de Recursos-a fer aportacions de les seves experiències d'innovació: didàctiques, organitzatives, lúdico-festives, etc., per tal de donar-les a conèixer i crear una xarxa d'intercanvi d'experiències renovadores.

3. Implicar els mitjans de comunicació del Camp de Tarragona i especialment els de la ciutat en la nostra celebració, per tal que es facin ressò dels diferents actes programats i tinguem opció a uns espais per publicar articles i reflexions diverses sobre l'educació. Podria ser l'espai: "25 anys de Renovació Pedagògica".

4. Continuar amb les nostres activitats d'hivern, que quedaran immerses i reforçades pels esdeveniments de la celebració, ja que la formació permanent ha estat durant molts anys un dels nostres trets d'identitat.

5. Engrescar el món de l'ensenyament i la societat que l'envolta perquè participi activament en els diferents actes programats: xerrades, debats, exposicions, vídeo-fòrum, etc. per tal que esdevinguin els protagonistes i transformar la ciutat, durant aquest curs, en una ciutat educadora.

6. Establir lligams amb la resta de la societat civil, institucions, la Universitat, que ens permetin poder continuar treballant plegats, col-laborar en altres projectes, mantenir canals de comunicació fluids i ràpids, és a dir, vincles que perdurin més enllà de la celebració i que ens enriqueixin mútuament.

7. Proposar una activitat col-lectiva per a grans $i$ petits, on deixar constància de la lluita per la defensa $i$ millora d'un Sistema d'Ensenyament Públic Català, element clau en la creació i trajectòria dels Moviments de Renovació Pedagògica de Catalunya.

Des d'aquestes ratlles, convidem la societat civil a tots els actes que estem preparant, actes d'àmbit general, lúdics, i que necessiten la participació de tothom. Perquè en la defensa de l'ensenyament públic, que és el nostre i també el vostre, tots i totes hi som necessaris. Estigueu alerta, us necessitarem. Gràcies.
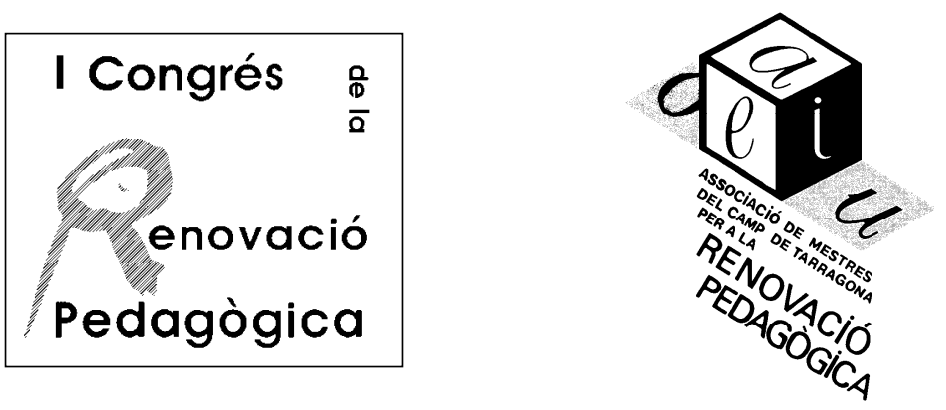

us esperem:

cada dia de 16 a 20 h a la

Cooperativa Obrera

C/ Fortuny, 23. Tarragona.

Tel. 220703

Apartat de Correus 690 